Guillermo Foladori

Pesquisador Visitante CNPq.

Programa de Doutorado em meio Ambiente e Desenvolvimento. UFPR.

Curitiba, Brasil.

E-mail:fola@cce.ufpr.br

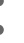

\title{
O Capitalismo e a crise ambiental
}

\section{Introdução}

Muito tem sido escrito sobre a crise ambiental contemporânea. $\mathrm{Na}$ maioria dos casos, culpa-se à indústria, fazendo clara menção ao grau de desenvolvimento tecnológico da sociedade antes que à sua estrutura de relações sociais. Para isso, existe um argumento de peso: nos ex países socialistas o grau de destruição da natureza foi igual ou pior que nos capitalistas, logo a causa deve ser procurada na indústria e não no tipo de relações sociais.

Nas próximas páginas vamos questionar este argumento. Consideramo-lo errado, desde qualquer ponto de vista. Contudo, aqui limitaremo-nos a destacar uma causa e manifestação da crise ambiental contemporânea que é exclusiva das relações capitalistas. Com isto, demonostraremos que se deve buscar a causa da crise ambiental, em primeira instância, no tipo de relações sociais de produção.

\section{O que é um ambiente? O que é uma crise ambiental?}

A resposta a estas perguntas provém da ecologia. Para qualquer espécie viva, o ambiente é a inter-relação com o meio abiótico e com as outras espécies vivas. Entre estes três grupos, espécie, meio abiótico e outras espécies, estabelece-se uma inter-relação de dependência dinâmica. Qualquer espécie extrai recursos do meio e gera dejetos. Quando a extração de recursos ou a geração de dejetos é maior do que a capacidade do ecossistema de reproduzi-los ou reciclá-los, estamos frente à depredação e/ou poluição, as duas manifestações de uma crise ambiental.

De outra parte, qualquer ecossistema tem uma certa capacidade de carga de uma espécie. Isto é, ele pode manter e reproduzir um certo número de indivíduos. Quando a população cresce demais, rompendo o equilíbrio dinâmico do sistema, se produz uma crise ambiental.
É comum extrapolar estes raciocínios para a sociedade humana e a crise ambiental contemporânea. Alguns autores falam da "marca d'água" que os barcos possuem, para assinalar que se a sociedade humana produz além de um certo nível, corre o risco de sobrecarregar o ecossistema e ir-se a pique. Ou falam da produção ilimitada da sociedade industrial em direta oposição aos recursos materiais finitos do planeta Terra, fazendo menção explícita à depredação e poluição da natureza. Não obstante, estas extrapolações resultarem atrativas, são equivocadas. Perdem de vista a especificidade humana.

Para qualquer espécie, a relação com o seu meio ambiente é basicamente a que ela estabelece em bloco com o meio abiótico e com o resto das espécies vivas, como uma interdependência dinâmica. Com a espécie humana o mesmo não ocorre. Uma sociedade humana não estabelece relações com o seu entorno na forma de bloco,
Raízes,

Ano XVIII,

$N^{\circ} 19$, maio/99 
mas sim por grupos e classes sociais, e de maneira desigual. No resto das espécies vivas, as diferenças individuais não se acumulam para formar classes distintas. Cada geração deve começar do zero ${ }^{1}$. Pelo contrário, os seres humanos acumulam a informação extra-corporal em instrumentos, utensílios, espaços construídos etc. Mas esta acumulação não é da sociedade como um todo, mas da cada classe social que transmite às gerações seguintes aquilo que logrou. É uma diferença no acesso aos recursos naturais virgens ou aqueles transformados pelas gerações passadas. Para a espécie humana, então, o ambiente não é só a interrelação com o meio abiótico e o resto dos seres vivos, como acontece com as outras espécies vivas. Existem ambientes diferentes para cada classe social, constituídos em primeiro lugar pelas restrições impostas pelas outras classes sociais da mesma espécie humana; só a partir destes condicionantes é que se estabelecem os relacionamentos com os outros seres vivos e o material abiótico.

Quando lemos que a causa da crise ambiental é a sociedade industrial como um todo, porque é a indústria, per se, quem polui ou depreda, não podemos mais nos surpreender pelo alto conteúdo ideológico da proposta. Este ponto de vista considera a sociedade capitalista como sendo homogênea, semelhante a qualquer outra espécie de animal. Claro que o argumento de que a sociedade socialista também poluía e depredava é atrativo, mas é enganoso. As conseqüências podem ser semelhantes, mas as causas também podem ser diferentes. Duas pessoas podem apresentar uma urticária, uma por ter ingerido um alimento indigesto, outra pelo contato com a planta da urtiga. Para a cura é necessário conhecer a causa. No primeiro caso, requer-se mudar a alimentação; no segundo, se distanciar da urtiga. $\mathrm{O}$ fato de tanto a sociedade socialista quanto a capitalista depredarem e poluírem não significa que o façam devido às mesmas forças. Nesse sentido, a identidade é enganosa; iguala as manifestações sem prestar atenção às diferenças nas causas. Neste momento não analisaremos estas diferenças, mas consideraremos uma manifestação da crise ambiental exclusiva da sociedade capitalista, como também é exclusiva a causa que a provoca. Isto demonstrará, sem deixar dúvidas, a responsabilidade das relações sociais (no caso as capitalistas), e não da indústria em geral, para com a crise ambiental contemporânea.

\section{A depredação da própria so- ciedade humana: o desemprego}

Nunca na história da humanidade existiu uma sociedade geradora de desemprego de forma estrutural. Muitos diagnósticos sobre a situação ambiental consideram a pobreza ou o crescimento populacional como um problema ambiental. Esta não é senão uma forma discreta de tratar o desemprego. São pobres os que não têm trabalho, e quando se fala de excedente populacional se faz referência explícita àqueles países que têm taxas de crescimento demográfico "não desenvolvidas”, ou seja, acima de $2 \%$ anual. Trata-se dos países pobres. De maneira que pobreza e crescimento populacional vão de mãos dadas. E, ambas as variáveis podem ser claramente identificadas com aquela população que não entra no mercado de trabalho ou o faz de forma marginal ou limitada. São as relações de mercado, as relações capitalistas que determinam qual população é excedente e quem são os pobres. Além disso, está amplamente demonstrado que a quantidade de filhos por família é antes de mais nada uma questão econômica. A força de trabalho é a primeira fonte energética. Quando não se dispõe de energias alternativas, as famílias recorrem ao trabalho humano $^{2}$.

- ${ }^{1}$ Quando as diferenças individuais se acumulam, fazem-no pela via biológica, o qual se traduz - num momento determinado no surgimento de outra espécie.

- ${ }^{2}$ O Canadá e os EUA têm um consumo energético anual de 9 e 7.5 TEP per capita, e uma taxa

- anual de crescimento demográfico de $0,8 \%$. Enquanto que a Ásia e a Africa, com uma taxa de

- consumo energético anual de 0.4 TEP devem compensá-la com um incremento demográfico

- de $2.4 \mathrm{e} 3.0 \%$ anual. 
Os diagnósticos que colocam a pobreza ou o incremento populacional como causa da crise ambiental apresentam a realidade de cabeça virada. Eles vêem na urticária um potencial de contágio, em lugar de olhar para a enfermidade que a produz, isto é, as relações capitalistas. A pobreza ou incremento populacional não são senão conseqüências, manifestações da falta de acesso ao mercado capitalista. Por isso, a causa destas manifestações são as próprias relações capitalistas, que geram pobreza e pressionam para a explosão demográfica. Por sua vez, ambas as variáveis são conseqüências do desemprego estrutural, uma características exclusiva da sociedade capitalista.

A produção capitalista inaugura, pela primeira vez na história da humanidade, um sistema de produção cujo objetivo não é a satisfação direta das necessidades, mas a obtenção dum lucro em dinheiro. Obtém-se este lucro através da concorrência no mercado. Uns ganham enquanto outros perdem. Não há forma alguma de que todos ganhem simultaneamente.

As causas do desemprego e a conseqüente pobreza têm a ver, em exclusividade, com as relações capitalistas e a combinação de duas tendências. De um lado, a substituição do trabalho vivo pelas máquinas, aquilo que hoje está na moda em chamar de desemprego tecnológico, ocultando sob um disfarce técnico neutro a responsabilidade de um tipo determinado de relações sociais. De outro, a peculiaridade do funcionamento do sistema capitalista, que reconhece como membro de sua sociedade a quem vende mercadorias, ainda que seja sua própria capacidade de trabalhar. O desempregado que nem produz, nem pode vender-se a si próprio por tempo, fica à margem da riqueza.

A lei de substituição de homens por máquinas conhece-se como a tendência ao acréscimo da composição orgânica do capital. Esta lei vem se manifestando contraditoriamente desde a própria revolução industrial. Contraditoriamente, porque enquanto uma empresa melhorava o capital fixo e deslocava operários, outras surgiam, absorvendo de alguma forma o pessoal excedente das primeiras. Para cada grande revolução tecnológica este movimento de deslocamento e absorção se alterava, em favor do deslocamento e em detrimento das novas absorções. Com a revolução da micro-eletrônica aplicada à produção, desde meados dos anos setenta, a situação tornou-se mais crítica.

O aumento da produtividade do trabalho como resultado da aplicação de melhores e mais sofisticadas tecnologias tem convertido em supérflua uma boa parte do trabalho humano mundial. No Japão, entre 1973 e 1987 o produto aumentou em $4,6 \%$ anual, mas no mesmo período, o emprego cresceu apenas $0,9 \%$, constituindo-se a brecha entre um percentual e o outro o indicador deste tipo de desemprego, resultado do aumento da produtividade do trabalho (UNDP, 1993:35)

Segundo um informe do PNUD, divulgado em 16 de outubro de 1997, a situação da pobreza no mundo piorou nos últimos 50 anos, tanto em termos absolutos como relativos. Há cinqüenta anos, em 1947, o número de pobres era de 400 milhões, o que eqüivalia a $17,4 \%$ da população mundial. Em 1997, o número de pobres é de 1,3 bilhões, o que representa $22,8 \%$ da população mundial ${ }^{3}$. Ou seja, nos últimos cinqüenta anos a quantidade de pobres aumentou em 900 milhões e em termos relativos quase alcançou $1 / 4$ da população mundial. Estes dados, por si próprios, mostram que no mundo capitalista a pobreza tende a aumentar, apesar dos enormes desenvolvimentos tecnológicos e da produtividade do trabalho.

Outras cifras sumamente eloqüentes aparecem no informe das Nações Unidas e confirmam a asseveração de que a tendência ao desemprego estrutural e a conseqüente pobreza é exclusiva do regime capitalista de produção. Efetivamente, se se tomam os dados da Europa Oriental e da ex-União Soviética cons- 
tata-se que os pobres passaram de 4 milhões em 1987 para ' 120 milhões em 1997, aumento registrado desde anos antes da derrubada do sistema socialista e a entrada num regime capitalista. E, se não for suficiente, podemos considerar o caso da China, que diminuiu em $50 \%$ o número de pessoas vivendo por debaixo do nível de pobreza nos últimos 20 anos, enquanto os países capitalistas, com sua despregadura de riqueza e recursos, aumentaram o número de pobres no mesmo período.

Caso não sejam formuladas políticas mundiais que revertam as tendências econômicas próprias do mercado, nem estes pobres e, menos ainda os filhos deles, obterão emprego.

\section{Relações capitalistas e ecologia}

O relacionamento entre a economia capitalista e os problemas ambientais obriga-nos a recolocar teoricamente a questão ambiental.

As primeiras aproximações ao estudo da questão ambiental provêm da ecologia. A ecologia surge como uma área da biologia para estudar a interrelação dos organismos e comunidades de organismos com o meio ambiente. As considerações mais avançadas da ecologia incorporam o ser humano, e assim a ecologia passa a se converter numa ciência interdisciplinar, que pretende estabelecer uma conexão entre as ciências físico-naturais e as ciências sociais (Odum, 1980).
Numa primeira aproximação, a análise ecológica parece dar conta tanto da relação de qualquer espécie viva com seu meio ambiente, como das relações que a espécie humana estabelece com o meio ambiente. Em qualquer caso, analisam-se as inter-relações entre os organismos e os fluxos de materiais e energia. Não obstante, um olhar mas atento mostra certas complicações. As dificuldades vêm das diferenças de tratamento dos grupos de indivíduos enquanto membros da espécie humana ou de qualquer outras espécies vivas. Para estas últimas, o relacionamento com o meio ambiente é, dentro de certos limites, homogêneo. Homogêneo no sentido em que os distintos indivíduos que compõem uma espécie possuam, em essência, os mesmos "instrumentos" - que são naturais - para seu relacionamento. O que significa igual requerimento de recursos, igual produção de resíduos e concorrência pelos mesmos nichos ecológicos. É claro que a igualdade é relativa, daí falarmos que essencialmente dispõem dos mesmos instrumentos. A biologia evolucionista explica, claramente, que cada indivíduo é diferente. Não obstante, ditas diferenças não são essenciais no que diz respeito ao relacionamento com o meio ambiente. Elas se tornam essenciais quando surge uma nova espécie. Com todas as dificuldades que existem na determinação do que é uma espécie, é evidente que a prática da vida mostra esta distinção entre diferenças essenciais entre espécies distintas e diferenças entre indivíduos de uma mesma espécie, que para efeitos de exposição consideraremos não essenciais. Então, internamente a cada espécie os indivíduos que a compõem, ou os grupos de indivíduos, dispõem do mesmo instrumental para enfrentar ao meio. Cada geração começa de zero, no sentido de que os indivíduos possuem uma bagagem genética que os fazem semelhantes (por isso capazes de se reproduzir entre si), e uma constituição fenotípica com recursos semelhantes para estender-se e relacionar-se com o meio ambiente. Porém, é claro que em termos mais estritos e numa análise mais profunda existem marcadas diferenças individuais ao interior de cada espécie. E, seguramente, dependendo do nicho ecológico onde se encontram, alguns grupos de indivíduos têm diferenças que no longo prazo resultarão determinantes para sua sobrevivência e reprodução em relação a outros indivíduos da mesma espécie que se situam em nichos ecológicos menos favoráveis. Mas, inclusive estas diferenças, distinguem grupos de indivíduos de um nicho em relação a outro nicho. Ao interior de cada nicho as diferenças individuais só são diferenças biológicas que fazem que cada geração arranque de zero.

No caso do ser humano existe uma diferença notável. O relacionamento com o meio ambiente é principal e crescentemente mediado pelas coisas produzidas. A bagagem genética, assim como o nicho ecológico onde se situa, poderá ter sido importante na origem do gênero homo, e talvez, também da espécie homo sapiens, mas é cada vez menos importante na medida do avanço da produtividade do trabalho humano. 
A conseqüência evidente deste comportamento mediado com o meio é que as coisas estão separadas do indivíduo biológico, o que permite a sua acumulação através do tempo. Mais ainda, como esta acumulação não é da sociedade como um todo, nem de grupos segundo o nicho ecológico onde se encontram, mas sim de grupos de indivíduos segundo a sua propriedade e acesso aos meios de produção (que são os que permitem, por sua vez, produzir o resto das coisas) e à riqueza em geral, resulta que as leis sociais que guiam o reparto dos meios de produção condicionam um acesso diferenciado à riqueza natural.

Daí que o ponto de partida para entender o comportamento do ser humano com o ambiente não seja estender a análise ecológica para abranger a sociedade humana, mas entender como cada forma de organização econômica da sociedade humana explica um determinado tipo de relacionamento ecológico.

A análise das implicações das relações sociais capitalistas com o meio ambiente permite-nos extrair algumas conclusões, que mostram diferenças de grau e de essência a respeito de outras formas de organização social. De grau, porque a persecução do lucro, como lógica interna econômica, conduz a uma tendência à produção ilimitada; diferente das outras sociedades humanas na história que apresentam limites à produção em relação à satisfação de suas necessidades. De essência, porque pela primeira vez na história da sociedade humana, o sistema capitalista gera desemprego de maneira crescente e estrutural, mostrando com maior nitidez que as contradições ao interior da sociedade humana são o aspecto mais candente da crise ambiental.

\section{Conclusões}

As relações sociais capitalistas geram tendências de comportamento com o meio ambiente que lhe são particulares. Um olhar superficial pode não ver esta especificidade, devido ao que o resultado geral da poluição e depredação abrange todas as sociedades humanas independentemente de sua especificidade histórica. Mas diferem tanto na causa, quanto na forma, amplitude e ritmo com que se apresentam. A produção capitalista implica tendências exclusivas.

A tendência exclusiva mais geral é a produção ilimitada. Uma das "queixas", se assim podemos chamá-la, do movimento ambientalista que tem sido dirigido à sociedade moderna é seu crescimento ilimitado. O crescimento ilimitado da sua produção seria a causa de uma poluição e depredação também ilimitadas e segundo alguns autores, de uma sobre-capacidade de carga do Planeta. Mas esta tendência ilimitada à produção não é uma conseqüência natural da espécie humana, mas sim particular da produção capitalista. É claro que a teoria econômica neoclássica e keynesiana têm se encarregado de divulgar o suposto sobre o qual elas se construíram, isto é, que o ser humano tem necessidades ilimitadas. Mas isto ja- mais foi demonstrado, pelo contrário, tanto a história econômica quanto a antropologia têm mostrado este equívoco. A tendência à produção ilimitada é resultado direto e necessário de uma organização econômica que gira em torno da produção de lucro, e não da satisfação das necessidades. Por isso, é impossível entender a crise ambiental sem partir da compreensão da dinâmica econômica da sociedade capitalista. Por isso, também, resultam fúteis as críticas à produção ilimitada que não encaram, ao mesmo tempo, as críticas à organização capitalista da sociedade humana.

A tendência exclusiva mais grave do capitalismo é a geração de população excedente. Aqui, à diferença em relação às outras formas de organização econômica não é só de grau, mas quanto ao maior aumento, ou ritmo mais rápido, senão de essência. Não tem existido organização econômica na história da humanidade que gere população excedente como algo "natural" e necessário. Esta restrição que exercem as classes possuidoras ou proprietárias sobre as despossuídas não tem comparação nas outras espécies de seres vivos. É como se um grupo de pássaros se encarregasse de tirar as asas dos pombinhos de outros grupos de sua mesma espécie ao nascer, para deixá-los impossibilitados de acessar aos meios de vida. Ou como se um grupo de gatos se encarregasse de mutilar as garras de outros grupos, deixando-os indefesos frente ao meio ambiente. Também aqui as relações sociais se ante- 
põem e determinam as relações ecológicas.

Em resumo, a conclusão mais geral é que as relações sociais entre os seres humanos condicionam qualquer tipo de relações ecológicas. A ecologia humana, para ser conseqüente, deve se converter em ecologia política.

\section{Biografia}

Folha de São Paulo. 1997 "Triplica número de pobres". Folha de São Paulo. 17/10/97. São Paulo.

Odum, Eugene. 1980 Ecologia. Compañia Editorial Continental S.A. México, DF.

UNDP (United Nations Development Programme) $1993 \mathrm{Hu}-$ man Development Report. Oxford University Press. New York/Oxford. 